\title{
Future Doctors' Nutrition-Related Knowledge, Attitudes and Self-Efficacy Regarding Nutrition Care in the General Practice Setting: A Cross-Sectional Survey
}

\author{
Victor Mogre $^{1,2} \cdot$ Paul A. Aryee ${ }^{3}$ - Fred C. J. Stevens ${ }^{2}$ - Albert J. J. A Scherpbier ${ }^{2}$
}

Published online: 11 May 2017

(C) The Author(s) 2017. This article is an open access publication

\begin{abstract}
Background Doctors are in a good position to provide nutrition advice to patients. However, doctors and medical students find their nutrition education to be inadequate. We evaluated nutrition-related knowledge, attitudes and self-efficacy in a sample of future doctors. Furthermore, we investigated the association between nutrition-related knowledge, attitude and self-efficacy. We also compared nutrition-related knowledge, attitudes and self-efficacy with level of clinical training. Methods Following a cross-sectional design, the nutritionrelated knowledge, attitudes and self-efficacy of 207 undergraduate clinical-level medical students (referred to as future doctors) was measured using a questionnaire. Items of the questionnaire were derived from previously validated survey instruments. Descriptive statistics of mean and standard deviation was used to describe the data.

Results Future doctors had a mean knowledge score of $64 \%$. Their mean knowledge scores in the nutrition topics assessed were $41 \%$ for 'malnutrition in children', $59 \%$ for 'diabetes and obesity' and $73 \%$ for 'nutrients, energy and their deficiencies'. Future doctors' attitudes towards nutrition care were generally positive but were uncertain in the effectiveness of health
\end{abstract}

Victor Mogre

vmogre@uds.edu.gh

1 Department of Health Professions Education and Innovative Learning, School of Medicine and Health Sciences, University for Development Studies, P. O. Box TL, 1883 Tamale, Ghana

2 School of Health Professions Education, Faculty of Health, Medicine and Life Sciences, Maastricht University,

Maastricht, The Netherlands

3 Department of Community Nutrition, School of Allied Health Sciences, University for Development Studies, Tamale, Ghana education in changing the lifestyle of patients. They felt inadequate in their self-efficacy to provide nutrition care. Attitudes towards nutrition care correlated $(r=0.371, p<0.001)$ positively with self-efficacy to provide nutrition care. Level of clinical training was associated to nutrition-related knowledge of the students.

Conclusion Future doctors had positive attitudes towards nutrition care but showed important knowledge gaps and also felt inadequate in their confidence to provide nutrition care. Attitudes may be important in nutrition care self-efficacy.

Keywords Attitudes $\cdot$ Confidence $\cdot$ Medical education . Nutrition education · Ghana and self-efficacy

\section{Introduction}

There is growing concern for the rising trend of nutrition and diet-related diseases in many sub-Saharan African countries. Undernutrition, diabetes, overweight and obesity are dietrelated and are now diseases of public health concern in the sub-region [1, 2]. Many children (28 million) in Central and West Africa are stunted, underweight or wasted [3, 4]. On the other hand, diabetes, overweight and obesity have also been estimated to be rising in the sub-region with close to 14.2 million people affected and estimated to rise to 34 million by 2040 [1].

Undernutrition in the first 1000 days of a child's life is associated with mortality, morbidity, impaired cognitive ability and poor school performance [4-6] and is strongly associated with the development of non-communicable diseases such as overweight and obesity, diabetes and hypertension.

In sub-region where rising prevalence of diet-related diseases could increase the health burden in terms of morbidity and costs related to the treatment or care of patients, 
improving nutrition could lead to a reduction in the situation. Nutrition educators, specialists and multidisciplinary support teams are necessary to cater for the needs of patients in subSaharan Africa in order to reduce the ever increasing epidemics. Nevertheless, among all the identifiable human resources, medical doctors are regularly considered as credible sources of nutrition advice [7-10] and are better placed to provide dietary and nutrition advice to patients.

In evaluating the status of nutrition education in the medical curricula, a number of studies in the USA [11-13] and other high-income countries $[10,14,15]$ have found it to be inadequate. This has been corroborated by medical doctors reporting inadequate training in nutrition education during medical school, inadequate knowledge and skills in nutrition and feeling less efficacious in their ability to effectively provide nutrition care to patients [10,16-19]. A number of factors have been noted for this situation including time limitations in the medical curriculum, resistance to the addition of new courses or lecture, and low priority for nutrition education [20-23]. Other factors include the curriculum emphasizing on disease treatment but not disease prevention and lack of physician nutrition specialists or other nutrition educators on faculty as these professionals serve as role models to both medical students and residents for addressing nutrition in patient interactions [24-26].

Unlike in the USA and other developed countries, the issue of nutrition in medical education is scarcely explored in countries of sub-Saharan Africa, where increased prevalence of diet and nutrition-related diseases are persistent. In such settings, it would be most imperative to conduct an evaluation of the situation of nutrition education, the confidence, knowledge and attitudes of future medical doctors as a necessary step towards empowering them to be able to provide nutrition care to prevent and reduce the burden of diet-related diseases [27-33]. The findings of a recent realist review of educational interventions to improve nutrition care competencies and delivery by doctors and other healthcare professionals highlighted the importance of undertaking a needs assessment in this direction [34].

Previous findings have been equivocal in relating attitudes with knowledge and self-efficacy in nutrition [18, 35-37]. Even though one study has evaluated the association between attitudes, self-perceived proficiency and knowledge in a sample of internal medicine residents in the USA [35], no study have evaluated the relationship between knowledge, attitudes and self-efficacy in nutrition among undergraduate medical students. Thus, studies evaluating how these are related among future doctors are lacking.

Undertaking a needs assessment of future doctors' nutrition-related knowledge, attitudes and self-efficacy in sub-Saharan Africa using Ghana as a case example is likely to increase our understanding of the situation of nutrition education in sub-Saharan Africa. It will also provide baseline data to teachers, nutrition practitioners, researchers in health professions education and policy makers to inform efforts towards reforms in the medical curricula in the sub-region.

We thus intend to answer the following research questions.

1. What are future doctors' nutrition-related knowledge, attitudes towards and self-efficacy in nutrition care?

2. Does future doctors' nutrition-related knowledge relate to their attitudes towards and self-efficacy in nutrition care?

3. Does level of clinical training relate to future doctors' nutrition-related knowledge, attitudes towards, and selfefficacy in nutrition care?

\section{Methods}

\section{Ethics Statement}

All data collection methods and procedures complied with the guidelines of the Navrongo Health Research Centre Institutional Review Board (NHRCIRB) (Ethics Approval ID: NHRCIRB209) in Ghana, which subsequently approved the study. Each participant signed an informed consent form included in the questionnaire. All informed consent procedures were approved by the NHRCIRB.

\section{Study Design and Setting}

Following a cross-sectional design, participants of the study included undergraduate clinical-level medical students (referred to as future doctors in this study) of the University for Development Studies, School of Medicine and Health Sciences (UDS-SMHS), Ghana. Teaching and learning is organized around a problem-based learning, community-based education and service (PBL/COBES) curriculum. The PBL/ COBES curriculum is implemented through a series of themebased PBL blocks for the preclinical years and coordinated discipline-based clerkship rotations for the clinical years of training. Topics in nutrition are usually covered in the preclinical years and sparsely taught in the clinical years. Further information on the structure of medical education of the UDS-SMHS is published elsewhere [38, 39].

\section{Recruitment and Data Collection Procedures}

All future doctors were eligible to participate in the study. Prior to the commencement of data collection, students were informed about the study through announcements that were made before or at the end of usual lecture times depending on the time convenient for the announcement to be made. All data was collected using a paper-based anonymous survey instrument. Future doctors completed the survey after an end 
of rotation examination and returned it. The survey included information about the study and an informed consent to be signed before consenting to participate in the study. Voluntary participation was encouraged and students were assured of the confidentiality of their responses. Future doctors were incentivised with two pieces of candy upon the return of a completed survey instrument.

\section{Measures}

The survey instrument was used to assess future doctors' nutrition-related knowledge, attitudes towards, and selfefficacy in nutrition care (shown in Table 1). Nutritionrelated knowledge was assessed using 10 multiple choice questions. Topics covered were 'nutrients, energy and their deficiencies' (6 items), 'malnutrition in children' ( 2 items) and 'diabetes and obesity' ( 2 items). Items were adapted from previously validated nutrition knowledge tests $[35,40]$ and informed by common nutrition issues in Ghana. Each respondent was assigned a score of 1 for every correct answer, summed and computed out of $100 \%$. Future doctors' attitudes and self-efficacy regarding nutrition were evaluated using 11and 9-item measures, respectively. Items for the attitude measure were derived from a previously validated Nutrition in Patient Care Survey (NIPS) [41]. This measure had a Cronbach's alpha of 0.76. Possible responses spanned from strongly disagree to strongly agree on a 5-point Likert Scale. Items for the self-efficacy measure were also adapted from previously published surveys $[35,42,43]$. This scale had a Cronbach's alpha of 0.84 . Possible responses ranged from being very unconfident to being very confident on a 5-point Likert scale. From a list of three nutrition education resources (undergraduate medical curriculum, seminars/conferences and reading and self-directed learning), students were asked to determine the extent to which they felt those training resources contributed to their current nutrition-related knowledge. This item was derived from a previous survey [44]. Possible responses ranged from none to maximum on a 5-point Likert scale. Demographic characteristics such as gender and age were also assessed using the survey instrument. The final list of items was reviewed by a panel of experts and researchers in nutrition and health professions education and was found to be content valid. It was also pretested on a sample of 10 future doctors to assess understanding and comprehensibility. The responses of these participants were excluded from the final analysis.

\section{Statistical Analysis}

Statistical analyses were performed using IBM SPSS Statistics 21.0. Descriptive statistics of mean and standard deviation were used to explore and describe the data. Relationship between continuous variables and categorical variables were determined using independent $t$ test and one-way ANOVA where appropriate. Pearson product-moment correlation was used to examine associations among continuous variables. A $p$ value of less than 0.05 was considered significant in all statistical tests of significance. Figure was drawn using Graphpad prism.

\section{Results}

\section{Demographics}

From a total of 215 questionnaires distributed, 207 were returned (response rate $=96 \%$ ). With a mean age of $25.13 \pm 2.56$ years, $59.9 \%(n=124)$ were males, $38.2 \%$ $(n=79)$ in clinical year two and $30.9 \%(n=64)$ each in clinical year one and three.

\section{Nutrition-Related Knowledge}

Future doctors had an average knowledge score of $64 \%$ (shown in Table 2). Except for the 'malnutrition in children' topic, future doctors' mean scores in all of the individual topics were above average. Future doctors' scores in all the three nutrition topics differed by level of clinical training. In the 'nutrients, energy and their deficiencies' topic, future doctors in clinical year $1(77.6 \pm 13.0)$ scored significantly ( $p=0.017$ ) higher (vs and) than those in clinical years $2(73.3 \pm 13.0)$ and $2(69.6 \pm 20.0)$. Clinical year 3 students had higher mean scores than those in clinical year $1(74.6 \pm 35.5$ vs $28.0 \pm 33.2$ and $28.2 \pm 32.8, p<0.001)$ and two in the 'malnutrition in
Table 1 Description of survey sections

\begin{tabular}{ll}
\hline Section & Description of questions \\
\hline Knowledge & 10 questions evaluating future doctors' knowledge in nutrition \\
Attitudes & 11 questions exploring future doctors' attitudes towards nutrition \\
Self-efficacy & 9 questions evaluating self-perceived confidence in providing nutrition care \\
Nutrition education & 1 question exploring nutrition education resources commonly used by the future \\
$\quad$ resources & doctors \\
Demographics & 3 questions assessing students age, sex and level of clinical training \\
\hline
\end{tabular}


Table 2 Future doctors mean scores based on nutrition-related knowledge domains $(n=199)$

\begin{tabular}{lr} 
Nutrition topic & \multicolumn{1}{c}{$\begin{array}{l}\text { Mean } \pm \text { SD }) \\
(n=199)\end{array}$} \\
\hline Nutrients, energy and their deficiencies (6 items) & $73 \pm 15.5$ \\
Malnutrition in children (2 items) & $41 \pm 39.5$ \\
Diabetes and obesity (2 items) & $59 \pm 31.0$ \\
All topics (10 items) & $64.3 \pm 16.3$
\end{tabular}

Responses do not add up to 207 due to non-response for some of the items

children' topic. In addition, clinical year 3 students had higher mean scores than clinical year $1(69.3 \pm 31.0 \mathrm{vs}$ $55.5 \pm 30.0$ and $55.1 \pm 30.8, p=0.015)$ and two students in the 'diabetes and obesity' topic.

\section{Attitudes towards Nutrition Care}

Future doctors had a mean \pm SD attitude score of $41.13 \pm 5.39$ (maximum score $=55$ ). Almost $50 \%$ of the future doctors either disagreed or were uncertain of the effectiveness of health education in promoting patients' adherence to healthy lifestyle recommendations (shown in Table 3). Also, a substantial proportion of the future doctors were uncertain or disagreed in their competence to provide nutrition advice to patients. Future doctors' attitudes did not differ by level of clinical training $(p=0.243)$.

\section{Self-Efficacy in Nutrition Care}

Future doctors had a mean \pm SD self-efficacy score of $29.88 \pm 5.67$ (maximum score $=45$ ). As shown in Table 4, the majority of the future doctors were either less confident or uncertain in their ability to: recommend dietary patterns for patients with type 2 diabetes $(54.6 \%, n=107)$; manage severely malnourished children according to the WHO guidelines $(61.9 \%, n=122)$; provide examples of serving sizes, discussing essential fatty acids and heart health $(71.9 \%$, $n=141$ ); discuss calories per gramme of protein, carbohydrates and fat and their basic metabolic roles with patients $(65.0 \%, n=128)$ and provide nutrition education for a patient recently diagnosed with HIV infection $(62.4 \%, n=123)$. Nutrition care self-efficacy scores did not differ by level of clinical training $(p=0.086)$.

\section{Types of Nutrition Education Resources that Contributed to Future Doctors' Current Nutrition-Related Knowledge, Attitudes towards, and Self-Efficacy in Nutrition Care}

Reading and self-directed learning were the commonly used strategies to acquire information on nutrition (Fig. 1).

\section{Association between Knowledge, Attitudes and Self-Efficacy}

Future doctors' attitude towards nutrition care correlated positively with their self-efficacy scores $(r=0.371, p<0.001)$.

Table 3 Future doctors' attitudes towards nutrition care

\begin{tabular}{|c|c|c|c|c|}
\hline Nutrition care attitude items & Mean \pm SD & Disagree & $\begin{array}{l}\text { Neither agree nor } \\
\text { disagree }\end{array}$ & Agree \\
\hline $\begin{array}{l}\text { Discussing physical activity and nutrition information with patients in the general } \\
\text { practice is my responsibility }(n=200)^{\mathrm{a}}\end{array}$ & $3.71 \pm 0.95$ & $27(13.5 \%)$ & $26(13.0 \%)$ & $147(73.5 \%)$ \\
\hline $\begin{array}{l}\text { Nutrition assessment should be included in any routine appointment, just like diagnosis } \\
\text { and treatment }(n=198)\end{array}$ & $3.73 \pm 0.87$ & $20(10.1 \%)$ & $36(18.2 \%)$ & $142(71.7 \%)$ \\
\hline Nutrition counselling should be part of routine care for all physicians $(n=198)$ & $3.76 \pm 0.91$ & $20(10.1 \%)$ & $36(18.2 \%)$ & $142(71.7 \%)$ \\
\hline Nutrition counselling is not effective use of my professional time $(n=195)^{\mathrm{b}}$ & $3.64 \pm 1.08$ & $130(66.7 \%)$ & $29(14.9 \%)$ & $36(18.5 \%)$ \\
\hline Severe acute malnutrition represents a medical emergency $(n=198)$ & $4.22 \pm 0.87$ & $9(4.5 \%)$ & $24(12.1 \%)$ & $165(83.3 \%)$ \\
\hline Patient motivation is essential to achieving dietary change $(n=199)$ & $3.98 \pm 0.87$ & $14(7.0 \%)$ & $18(9.0 \%)$ & $167(83.9 \%)$ \\
\hline Patient will adopt a healthier lifestyle if counselled to do so $(n=198)$ & $3.83 \pm 0.84$ & $12(6.1 \%)$ & $35(17.7 \%)$ & $151(76.3 \%)$ \\
\hline $\begin{array}{l}\text { Physicians can have an effect on patients' dietary behaviour if they take the time to } \\
\text { discuss the problem }(n=200)\end{array}$ & $3.98 \pm 0.72$ & $7(3.5 \%)$ & $17(8.5 \%)$ & $176(88.0 \%)$ \\
\hline Most patients will try to change their lifestyle if I advise them to do so $(n=200)$ & $3.87 \pm 0.75$ & $10(5.0 \%)$ & $32(16.0 \%)$ & $158(79.0 \%)$ \\
\hline I believe I have adequate competence to provide nutrition advice to patients $(n=199)$ & $3.05 \pm 0.97$ & $56(28.1 \%)$ & $74(37.2 \%)$ & $69(34.7 \%)$ \\
\hline $\begin{array}{l}\text { For most patients, health education does little to promote adherence to a healthy } \\
\quad \text { lifestyle }(n=198)^{\mathrm{a}}\end{array}$ & $3.35 \pm 1.05$ & $100(50.5 \%)$ & $51(25.8 \%)$ & $47(23.7 \%)$ \\
\hline Total attitude score $(n=190)$ & $41.13 \pm 5.39$ & & & \\
\hline
\end{tabular}

In computing frequencies, strongly disagree and disagree were combined to yield 'Disagree'and strongly agree and agree were combined to yield 'Agree'. Responses do not add up to 207 due to non-response to some of the items

${ }^{a}$ Response scale: 1 = strongly disagree, $2=$ disagree, $3=$ neither agree nor disagree, $4=$ agree and $5=$ strongly agree

${ }^{\mathrm{b}}$ Reverse scored: $5=1,4=2,4=2,1=5$ 
Table 4 Future doctors' self-efficacy in providing nutrition care

Nutrition care self-efficacy items

Mean \pm SD Unconfident Neither confident nor Confident unconfident

Calculating my patients BMI and WHR based on gender $(n=197)$

Recommending dietary patterns for patients with type 2 diabetes $(n=196)$

Managing severely malnourished children according WHO guidelines $(n=197)$

Explaining the role of dietary cholesterol and saturated fat elevating blood lipids to patients $(n=197)$

Providing examples of a serving size of meat or dairy from the food guide pyramid to patients $(n=196)$

Discussing with lactating mothers the maternal and infant benefits and anticipated challenges with breastfeeding $(n=198)$

Discussing with patients the role of omega- 3 and omega- 6 fatty acids in heart health $(n=197)$

Discussing calories per gramme of protein, carbohydrates and fat and their basic metabolic roles with patients $(n=197)$

Providing nutrition education for a patient recently diagnosed with HIV infection $(n=197)$

Total mean $(n=194)$

$\begin{array}{lllr}3.81 \pm 0.83 & 13(6.6 \%) & 41(20.8 \%) & 143(72.6 \%) \\ 3.26 \pm 0.90 & 44(22.4 \%) & 63(32.1 \%) & 89(45.4 \%) \\ 3.18 \pm 1.02 & 53(26.9 \%) & 69(34.5 \%) & 75(38.1 \%) \\ 3.75 \pm 0.84 & 15(7.6 \%) & 45(22.8 \%) & 137(69.5 \%) \\ 2.88 \pm 0.98 & 68(34.7 \%) & 73(37.2 \%) & 55(28.1 \%) \\ 3.82 \pm 0.92 & 19(9.6 \%) & 27(13.6 \%) & 152(76.8 \%) \\ 3.19 \pm 1.01 & 48(24.4 \%) & 67(34.0 \%) & 82(41.6 \%) \\ 3.02 \pm 1.01 & 64(32.5 \%) & 64(32.5 \%) & 69(35.0 \%) \\ 3.09 \pm 1.01 & 62(31.5 \%) & 61(31.0 \%) & 74(37.6 \%) \\ 29.88 \pm 5.67 & & & \end{array}$

Response scale: 5 = very unconfident, $4=$ unconfident, $3=$ neither confident nor unconfident, $4=$ confident, $5=$ very confident. Very unconfident and unconfident were combined to yield 'Unconfident' and very confident and confident were combined to yield 'Confident'. Responses do not add up to 207 due to non-response for some of the items

However, their nutrition-related knowledge did not correlate with their attitudes $(r=-0.014, p>0.05)$ and self-efficacy in nutrition care $(r=0.073, p>0.05)$.

\section{Discussion}

We evaluated future doctors' nutrition-related knowledge, attitudes and self-efficacy in nutrition care. Associations among these variables were also investigated. Future doctors' nutrition-related knowledge levels were generally good but important knowledge gaps were noted. Their attitudes towards nutrition care were generally positive but they were unsure of their confidence in providing nutrition care to patients. Attitudes towards and self-efficacy in nutrition care correlated positively with each other, but neither correlated with nutrition-related knowledge. Comparable to previous studies future doctors answered $64 \%$ of all the knowledge items [35, $36,45]$.

An important finding of this study was that future doctors' nutrition-related knowledge was associated with their level of clinical training. In both the 'malnutrition in children' and 'diabetes and obesity' topics, clinical year 3 students performed better than clinical year 1 and 2 students. Given the fact that these topics are clinically oriented, clinical year 3 students might have had greater exposure than clinical year 1 and 2 students.

Conversely, students in clinical year 1 had higher scores than those in clinical years 2 and 3 in the 'nutrients, energy and their deficiencies' topic. This is a basic nutrition concept
Fig. 1 Types of nutrition education that have contributed to the future doctors' current nutrition-related competencies. Students were asked to indicate the extent to which each type of nutrition education had contributed to their current level of nutrition competency on a 4 point Likert scale. $1=$ None, $2=$ Slightly, $3=$ Moderate, and $4=$ Maximal

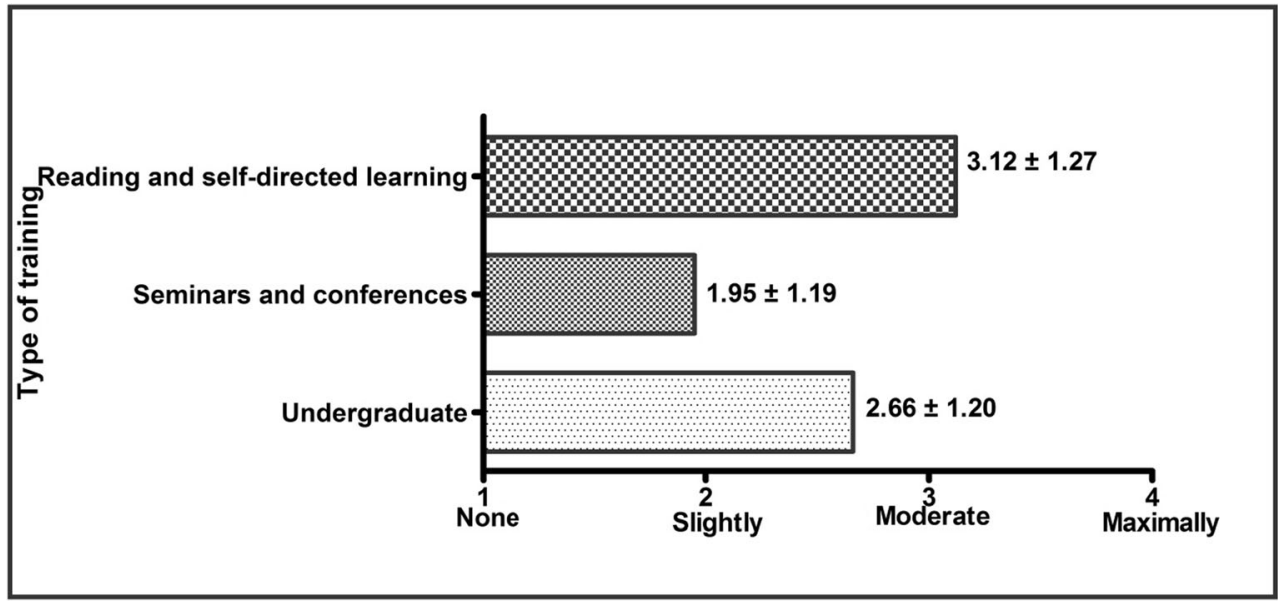


topic usually taught in preclinical years 1 and 2 . It is thus plausible that as the students' progressed through their training, they might have forgotten some of these basic nutrition concepts learned during the early part of their training. This finding gives credence to previous reports that students may fail to integrate basic concepts of nutrition with its clinical relevance if it is solely taught in the preclinical years of medical school [35]. Nutrition education should thus be integrated as a theme throughout the medical curriculum.

In examining future doctors' scores in the three nutrition topics, we found that their mean scores in the 'malnutrition in children nutrition' topic were the lowest compared to those scored in the other topics assessed. In addition future doctors' self-efficacy in the management of severely malnourished children was also among the lowest reported. This finding is concerning due to the fact that malnutrition is prevalent in Ghana but future doctors have inadequate knowledge in malnutrition in children and also lack confidence in their ability to manage malnourished children. Inadequacies in nutrition education and students being unsatisfied with their current nutrition education in the curriculum as reported previously [39] may be responsible for future doctors' poor competencies regarding nutrition. A revision of the entire curriculum to identify gaps and avenues to include nutrition topics of this nature is suggested.

In agreement with several studies, future doctors' attitudes towards nutrition care were generally positive $[10,35,36,40$, $45,46]$. However, there was notable uncertainty and disagreement regarding the effectiveness of health education in changing patient behaviour. Almost 50\% of the students felt that health education may not be effective in promoting patients' adherence to healthy lifestyles. Future doctors' apparent uncertainty in the effectiveness of health education has also been reported previously $[10,47]$. Taking note of the fact that health professionals' beliefs in the effectiveness of treatment guidelines could influence their practice behaviour [47], future doctors may not readily provide nutrition advice to patients at all times if they do not believe in the efficacy of such advice. Patient poor adherence/compliance, provider lack of counselling skills, lack of support systems for providers, and among others, could be responsible for future doctors' uncertainty in the effectiveness of health education.

Although the future doctors' attitudes towards nutrition care were positive, same could not be described for their self-efficacy in nutrition care. Out of nine aspects of providing nutrition care in the general practice setting, future doctors were generally confident in their ability to providing nutrition care in only three areas but reported being unconfident or uncertain in their ability to provide nutrition care for the rest, suggesting a low level of nutrition self-efficacy. These findings are similar to those reported by Crowley et al. among a sample of medical students from New Zealand [10].
The relatively low level of self-efficacy in nutrition care could be due to the format of nutrition training they received. Evidence from a previous study among these participants found lectures on selected topics to be the commonest and most frequent format of nutrition instruction [39]. Lectures may be a good way of introducing new concepts to students but lectures alone might not enhance self-efficacy as its opportunities for practical and clinical experiences are limited [48]. In identifying teaching and learning methods that could promote self-efficacy as well as attitudes in nutrition care, Mogre et al. [34] found the following to be important: role modelling by practicing physicians [49], role playing using either simulated or real patients [50-53], encouraging clinical bedside nutritional teaching [48], demonstrations and hands on practice sessions [49-52, 54-56], viewing and discussion of videos and Web-based cases [51,57].

In this study, we found that future doctors' attitudes correlated positively with their self-efficacy in nutrition care. Alluding to Bandura's social learning theory [58], future doctors' feelings of self-efficacy in nutrition care are necessary to promote favourable attitudes and nutrition practice behaviour. Evidence from previous findings found self-efficacy in nutrition care to be associated to nutrition practice behaviour in both medical students and practicing doctors $[51,53,54,56,59]$.

Self-directed learning being the highest contributor to future doctors' current nutrition-related competencies gives credence to previous findings that medical students value nutrition education and are ready to learn it if the opportunity is granted them $[35,46,60]$.

\section{Strengths and Limitations}

The findings of this study increase our understanding of the situation of nutrition training in medical education in Ghana and the larger sub-Saharan Africa region. The use of previously validated survey items and the use of nutrition experts to examine the content validity of the survey items enhanced confidence in our findings. Furthermore, using an instrument that is based on items relevant to global nutrition issues may help facilitate the recognition and prioritization of nutrition content in medical education and also makes the findings relevant to other countries in similar nutrition situations like Ghana.

However, our study is not without limitations. Its crosssectional nature makes it difficult to establish causality. Nonetheless, it gives a snapshot of the state of the nutrition competencies of future doctors and the situation of nutrition training in Ghana and probably the rest of sub-Saharan Africa. Our study reports on the nutrition competencies of students from a single medical school. This makes it difficult to generalize our findings. However, given the fact that this is the first study in Ghana as well as in several sub-Saharan African countries to investigate nutrition care competencies of future 
doctors, our findings serve as a basis and lay the foundation for future research in this subject. Another limitation of this study is the use of self-reports to measure nutrition competence making our findings liable to social desirability. Despite this observation, it is widely accepted that self-report measures of nutrition competence could be used as a proxy for actual measure of competence [42]. Findings of self-reports are usually as valid as are more elaborate and expensive tests [61].

\section{Future Research Directions}

Future studies should explore factors contributing to the current status of future doctors' nutrition care competencies and nutrition education in general identifying barriers and facilitators. Also, future studies should consider the effects of students' attitudes and self-efficacy on future nutrition practice behaviour and clinical outcomes of patients.

\section{Conclusion}

Future doctors had favourable attitudes towards nutrition care but had inadequate knowledge in some key nutrition topics. They were also uncertain in their confidence to provide nutrition care in the general practice setting. Enhancing doctors' attitudes and self-efficacy during medical school may be important in improving their nutrition practice behaviour.

Acknowledgements The authors wish to thank the students of the University for Development Studies, School of Medicine and Health Sciences, for their support and acceptance to take part in the research. The authors also wish to thank Benjamin Anane-Asamoah of the ICT Directorate of the University for Development Studies for helping with the framing of some of the items of the questionnaire.

\section{Compliance with Ethical Standards}

Conflict of Interest No conflicts of interest.

Funding No funding was received.

Open Access This article is distributed under the terms of the Creative Commons Attribution 4.0 International License (http:// creativecommons.org/licenses/by/4.0/), which permits unrestricted use, distribution, and reproduction in any medium, provided you give appropriate credit to the original author(s) and the source, provide a link to the Creative Commons license, and indicate if changes were made.

\section{References}

1. IDF (2015) IDF Diabetes Atlas 7th Edition. 7th Edition edn.,

2. UNICEF (2013) Improving child nutrition: the achievable imperative for global progress. United Nations Children's Fund,

3. UNICEF, WHO, World Bank (2015) Levels and trends in child malnutrition: UNICEF-WHO-World Bank joint child malnutrition estimates. New York.
4. UNICEF (2016) Undernutrition contributes to nearly half of all deaths in children under 5 and is widespread in Asia and Africa. UNICEF. http://data.Unicef.Org/nutrition/malnutrition.Html. Accessed 27/07/2016 2016.

5. United Nations Children's Fund. Improving child nutrition: the achievable imperative for global progress. New York; 2013.

6. Ainsworth M (2010) What can we learn from nutrition impact evaluations?: independent evaluation group studies. The World Bank, Washington, D.C. DOI:DOI: 10.1596/978-0-8213-8406-0.

7. American Dietetic Association (2008) Nutrition and you: trends 2008. Report of results American Dietetic Association.

8. American Dietetic Association (2011) Nutrition and you: trends 2008. Report of Results.

9. Abramson S, Stein J, Schaufele M, Frates E, Rogan S. Personal exercise habits and counseling practices of primary care physicians: a national survey. Clin J Sport Med. 2000;10(1):40-8.

10. Crowley J, Ball L, Han DY, Arroll B, Leveritt M, Wall C (2014) New Zealand medical students have positive attitudes and moderate confidence in providing nutrition care: a cross-sectional survey. Journal of Biomedical Education.

11. Mihalynuk TV, Coombs JB, Rosenfeld ME, Scott CS, Knopp RH. Survey correlations: proficiency and adequacy of nutrition training of medical students. J Am Coll Nutr. 2008;27(1):59-64.

12. Adams KM, Lindell KC, Kohlmeier M, Zeisel SH. Status of nutrition education in medical schools. Am J Clin Nutr. 2006;83(4): 941S-4S.

13. Adams KM, Kohlmeier M, Powell M, Zeisel SH. Nutrition in medicine: nutrition education for medical students and residents. Nutr Clin Pract. 2010;25(5):471-80. doi:10.1177/0884533610379606.

14. Chung M, van Buul V, Wilms E, Nellessen N, Brouns F. Nutrition education in European medical schools: results of an international survey. Eur J Clin Nutr. 2014;68(7):844-6.

15. Gramlich LM, Olstad DL, Nasser R, Goonewardene L, Raman M, Innis S, Wicklum S, Duerksen D, Rashid M, Heyland D. Medical students' perceptions of nutrition education in Canadian universities. Appl Physiol Nutr Metab. 2010;35(3):336-43.

16. Tziraki C, Graubard BI, Manley M, Kosary C, Moler JE, Edwards BK. Effect of training on adoption of cancer prevention nutritionrelated activities by primary care practices: results of a randomized, controlled study. J Gen Intern Med. 2000;15(3):155-62.

17. Glanz K, Gilboy MB. Physicians, preventive care, and applied nutrition: selected literature. Acad Med. 1992;67(11):776-81.

18. Krause T, Fox H. Nutritional knowledge and attitudes of physicians. J Am Diet Assoc. 1977;70(6):607-9.

19. Soltesz KS, Price JH, Johnson LW, Telljohann SK. Perceptions and practices of family physicians regarding diet and cancer. Am J Prev Med. 1994;11(3):197-204.

20. St Jeor ST, Krenkel JA, Plodkowski RA, Veach TL, Tolles RL, Kimmel JH. Medical nutrition: a comprehensive, school-wide curriculum review. Am J Clin Nutr. 2006;83(4):963S-967.

21. Bruer RA, Schmidt RE, Chapel T (1993) Nutrition education for physicians: alternative federal roles for creating an improved system. Richard Schmidt Associates,

22. Walker WA. Innovative teaching strategies for training physicians in clinical nutrition: an overview. J Nutr. 2003;133(2):541S-3S.

23. Makowske M, Feinman RD. Nutrition education: a questionnaire for assessment and teaching Nutrition Journal. 2005:4. doi:10.1186/ 1475-2891-4-2.

24. Touger-Decker R. Nutrition education of medical and dental students: innovation through curriculum integration. Am J Clin Nutr. 2004;79(2):198-203.

25. Wong V, Millen BE, Geller AC, Rogers AE, Maury J, Prout MN. What's in store for medical students? Awareness and utilization of expert nutrition guidelines among medical school preceptors. Prev Med. 2004;39(4):753-9. 
26. Intersociety Professional Nutrition Education Consortium. Bringing physician nutrition specialists into the mainstream: rationale for the intersociety professional nutrition education consortium. Am J Clin Nutr. 1998;68(4):894-8.

27. Levine BS, Wigren MM, Chapman DS, Kerner J, Bergman R, Rivlin R. A national survey of attitudes and practices of primary-care physicians relating to nutrition: strategies for enhancing the use of clinical nutrition in medical practice. Am J Clin Nutr. 1993;57(2):115-9.

28. Kushner RF. Barriers to providing nutrition counseling by physicians: a survey of primary care practitioners. Prev Med. 1995;24(6):546-52.

29. Hiddink G, Hautvast J, Van Woerkum C, Fieren C, Van't Hof M. Consumers' expectations about nutrition guidance: the importance of primary care physicians. Am J Clin Nutr. 1997;65(6):1974S-9S.

30. Kolasa K. Developments and challenges in family practice nutrition education for residents and practicing physicians: an overview of the north American experience. Eur J Clin Nutr. 1999;53:S89-96.

31. Nicholas L, Roberts DC, Pond D. The role of the general practitioner and the dietitian in patient nutrition management. Asia Pac J Clin Nutr. 2003;12(1):3-8.

32. Singh H, Duerksen DR. Survey of clinical nutrition practices of Canadian gastroenterologists. Canadian Journal of Gastroenterology and Hepatology. 2006;20(8):527-30.

33. Coombs JB, Barrocas A, White JV. Nutrition care of older adults with chronic disease: attitudes and practices of physicians and patients. South Med J. 2004;97(6):560-6.

34. Mogre V, Scherpbier AJJA, Stevens F, Aryee P, Cherry MG, Dornan T (2016) A realist synthesis of educational interventions to improve nutrition care competencies and delivery by doctors and other healthcare professionals (accepted). BMJ Open.

35. Vetter ML, Herring SJ, Sood M, Shah NR, Kalet AL. What do resident physicians know about nutrition? An evaluation of attitudes, self-perceived proficiency and knowledge. J Am Coll Nutr. 2008;27(2):287-98.

36. Hu SP, Wu, M.Y. \& Liu, J.F. (1997) Nutrition knowledge, attitude and practice among primary care physicians in Taiwan. J Am College Nutr 16 (5):439-442.

37. Block JP, DeSalvo KB, Fisher WP. Are physicians equipped to address the obesity epidemic? Knowledge and attitudes of internal medicine residents. Prev Med. 2003;36(6):669-75.

38. Mogre V, Amalba A, Saaka M, Kyei-Aboagye K. Medical students' achievement on the bachelor of medicine, bachelor of surgery/ chirurgery final part I and II licensing examination: a comparison of students in problem-based learning, community-based education and service, and conventional curricula in Ghana. Journal of educational evaluation for health professions. 2014;11:10.

39. Mogre V, Stevens F, Aryee PA, Scherpbier AJ. Nutrition in medicine: medical students' satisfaction, perceived relevance and preparedness for. Health Professions Education: Practice; 2017.

40. Hyska J, Mersini E, Mone I, Bushi E, Sadiku E, Hoti K, Bregu A. Assessment of knowledge, attitudes and practices about public health nutrition among students of the University of Medicine in Tirana, Albania. South Eastern European Journal of Public Health. 2014;1(2014)

41. McGaghie WC, Van Horn L, Fitzgibbon M, Telser A, Thompson JA, Kushner RF, Prystowsky JB (2001) Development of a measure of attitude toward nutrition in patient care. American Journal of preventive medicine 20 (1):15-20. Doi:http://dx.Doi.Org/10.1016/ S0749-3797(00)00264-6.

42. Mihalynuk TV, Scott CS, Coombs JB. Self-reported nutrition proficiency is positively correlated with the perceived quality of nutrition training of family physicians in Washington state. Am J Clin Nutr. 2003;77(5):1330-6.

43. Weinsier RL, Boker JR, Brooks CM, Kushner RF, Visek WJ, Mark DA, Lopez-S A, Anderson MS, Block K. Priorities for nutrition content in a medical school curriculum: a national consensus of medical educators. Am J Clin Nutr. 1989;50(4):707-12.
44. Wynn K, Trudeau JD, Taunton K, Gowans M, Scott I. Nutrition in primary care current practices, attitudes, and barriers. Can Fam Physician. 2010;56(3):e109-16.

45. Walsh CO, Ziniel SI, Delichatsios HK, Ludwig DS. Nutrition attitudes and knowledge in medical students after completion of an integrated nutrition curriculum compared to a dedicated nutrition curriculum: a quasi-experimental study BMC medical education. 2011:11. doi:10.1186/1472-6920-11-58.

46. Spencer EH, Frank E, Elon LK, Hertzberg VS, Serdula MK, Galuska DA. Predictors of nutrition counseling behaviors and attitudes in US medical students. Am J Clin Nutr. 2006;84(3):655-62.

47. Laws RA, Kirby SE, Davies GPP, Williams AM, Jayasinghe UW, Amoroso CL, Harris MF. Should I and can I? A mixed methods study of clinician beliefs and attitudes in the management of lifestyle risk factors in primary health care. BMC Health Serv Res. 2008;8(1):44.

48. Powell-Tuck J, Summerbell C, Holsgrove G, Garrow J. Four years' experience of an undergraduate medical nutrition course. J R Soc Med. 1997;90(2):67-72.

49. Carson JAS, Gillham MB, Kirk LM, Reddy ST, Battles JB (2002) Enhancing self-efficacy and patient care with cardiovascular nutrition eduction. American Journal of preventive medicine 23 (4):296302. Doi:http://dx.Doi.Org/10.1016/S0749-3797(02)00518-4.

50. Hillenbrand KM, Larsen PG (2002) Effect of an educational intervention about breastfeeding on the knowledge, confidence, and behaviors of pediatric resident physicians. Pediatrics 110 (5). doi: 10.1542/peds.110.5.e59.

51. Ockene JK, Ockene IS, Quirk ME, Hebert JR, Saperia GM, Luippold RS, Merriam PA, Ellis S. Physician training for patientcentered nutrition counseling in a lipid intervention trial. Preventive Medicine: An International Journal Devoted to Practice and Theory. 1995;24(6):563-70.

52. Gance-Cleveland B, Sidora-Arcoleo K, Keesing H, Gottesman $\mathrm{MM}$, Brady M. Changes in nurse practitioners' knowledge and behaviors following brief training on the healthy eating and activity together (HEAT) guidelines. J Pediatr Health Care. 2009;23(4): 222-30.

53. Conroy MB, Delichatsios HK, Hafler JP, Rigotti NA. Impact of a preventive medicine and nutrition curriculum for medical students. Am J Prev Med. 2004;27(1):77-80. doi:10.1016/j.amepre.2004.03. 009.

54. Eisenberg DM, Miller AM, McManus K, Burgess J, Bernstein AM (2013) Enhancing medical education to address obesity: "See one. Taste one. Cook one. Teach one.”. JAMA Intern Med 173 (6):470 472.

55. Schlair S, Hanley K, Gillespie C, Disney L, Kalet A, Darby PC, Frank E, Spencer E, Harris J, Jay M. How medical students' behaviors and attitudes affect the impact of a brief curriculum on nutrition counseling. J Nutr Educ Behav. 2012;44(6):653-7.

56. Levy J, Harris J, Darby P, Sacks R, Dumanovsky T, Silver L. The primary care nutrition training program: an approach to communication on behavior change. Health Promot Pract. 2011;12(5):761-8.

57. Carson JAS, Gillham MB, Kirk LM, Reddy ST, Battles JB. Enhancing self-efficacy and patient care with cardiovascular nutrition education. Am J Prev Med. 2002;23(4):296-302.

58. Bandura A (1997) Self-efficacy: the exercise of control. Macmillan,

59. Dacey M, Arnstein F, Kennedy MA, Wolfe J, Phillips EM. The impact of lifestyle medicine continuing education on provider knowledge, attitudes, and counseling behaviors. Medical teacher. 2013;35(5):e1149-56.

60. Weinsier RL, Boker JR, Feldman EB, Read MS, Brooks CM. Nutrition knowledge of senior medical students: a collaborative study of southeastern medical schools. Am J Clin Nutr. 1986;43(6):959-68.

61. Baird LL. Using self-reports to predict student performance. Research Monograph No. 1976;7 